\section{6 \\ $\frac{201}{4-9}$}

RFP-1997

RFP-1997

February 14, 1973

‘
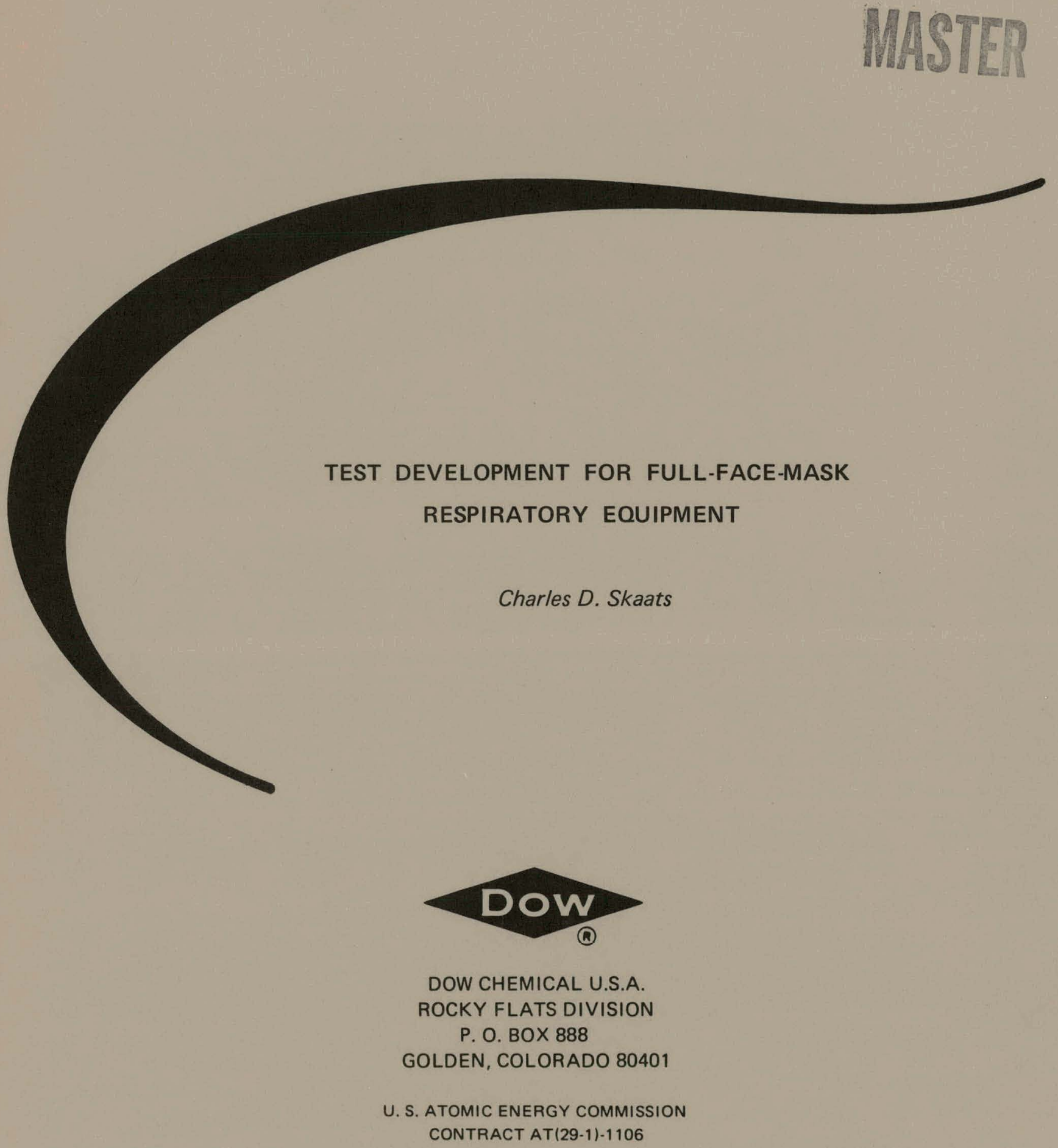

DOW CHEMICAL U.S.A. ROCKY FLATS DIVISION

P. O. BOX 888

GOLDEN, COLORADO 80401

U. S. ATOMIC ENERGY COMMISSION

CONTRACT AT(29-1)-1106 


\section{DISCLAIMER}

This report was prepared as an account of work sponsored by an agency of the United States Government. Neither the United States Government nor any agency Thereof, nor any of their employees, makes any warranty, express or implied, or assumes any legal liability or responsibility for the accuracy, completeness, or usefulness of any information, apparatus, product, or process disclosed, or represents that its use would not infringe privately owned rights. Reference herein to any specific commercial product, process, or service by trade name, trademark, manufacturer, or otherwise does not necessarily constitute or imply its endorsement, recommendation, or favoring by the United States Government or any agency thereof. The views and opinions of authors expressed herein do not necessarily state or reflect those of the United States Government or any agency thereof. 


\section{DISCLAIMER}

Portions of this document may be illegible in electronic image products. Images are produced from the best available original document. 


\section{LEGAL NOTICE}

This repurl was prepared as an account of work sponsored by the United States Government. Neither the United States nor the United States Atomic Energy Commission, nor any of their employees, nor any of their contractors, subcontractors, or their employees, makes any warranty, expressed or implied, or assumes any legal liability or responsibility for the accuracy, completeness or usefulness of any information, apparatus, product or process disclosed, or represents that its use would not infringe privately owned rights.

Printed in the United States of America

Available from the

Natinnal Technical Information Service

U. S. Department of Commerce

Springfield, Virginia 22151

Price: Printed Copy $\$ 3.00$; Microfiche $\$ 0.95$ 
Printed

r-bruary 14, 1973
RFP-1997

UC-41 HEALTH

AND SAFETY

TID-4500 (56th Ed.)

\title{
TEST DEVELOPMENT FOR FULL-FACE-MASK RESPIRATORY EQUIPMENT
}

Charles D. Skaats

\begin{abstract}
This report was prepared a
sponsor prepared as an account of work sponsored by the United States Government. Neither the United States nor the United States Atomic Energy Commission, nor any of their employees, nor any of their contractors, subcontractors, or their employees, makes any warranty, express or implied, or assumes any legal liability or responsibility for the, or assumes any. legal liability or responsibility. for the accuracy, com-

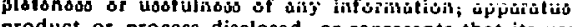
product or process disclosed, or represents that its use would not infringe privately owned rights.
\end{abstract}

DOW CHEMICAL U.S.A. ROCKY FLATS DIVISION

P. O. BOX 880

GOLDEN, COLORADO 80401

Prepared under Contract AT(29-1)-1106

for the

Albuquerque Operations Öffice

U. S. Atomic Energy Commission
SUBJECT DESCRIPTORS

Respiratory Protection 
RFP-1997 


\section{CONTENTS}

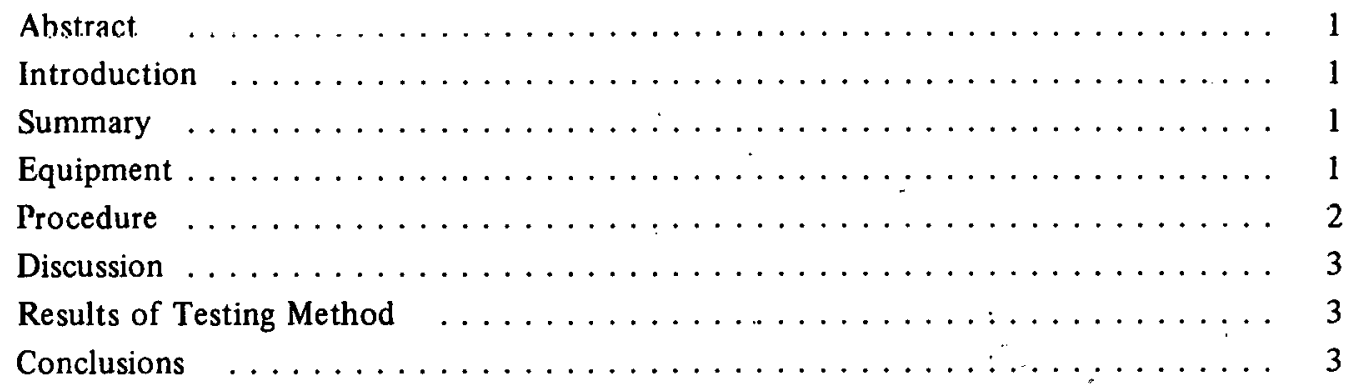


RFP-1997

\section{ACKNOWLEDGMENTS}

The author wishes to thank Edwin C. Hyatt and Charles P. Richards of the Respirator Research and Development Section, Industrial Hygiene Group, Los Alamos, New Mexico, for their advice and encouragement in the development of this test procedure. 


\title{
TEST DEVELOPMENT FOR FULL-FACE-MASK RESPIRATORY EQUIPMENT
}

\author{
Charles D. Skaats
}

\begin{abstract}
The test system for the full-face-mask respirator uses a monodisperse aerosol filter testing machine (the Q127 penetrometer) and two test heads from a Q14 gasmask-leakage tester.
\end{abstract}

The test heads utilize the entire system of the Q127 penetrometer. Dioctylphthalate (DOP) smoke from the aging chamber of the Q127 is supplied to a hand-operated nozzle for spraying mask assemblies and components.

A vacuum inside the mask assembly or component under test is maintained and controlled by the Q127.

The amount of smoke leaking into a defective mask is measured by the penetrometer. If more than $0.03 \%$ of smoke is detected, the mask assembly and components are repaired or rejected.

\section{INTRODUCTION}

Face-mask air-purifying respirators are used at Rocky Flats to protect personnel against inhalation of toxic materials. In the past, half-face masks were used for particulate protection against low and intermediate concentrations of airborne toxic materials.

At the Rocky Flats symposium on Safety in Plutonium Handling Facilities, April 13-16, 1971, a report was made on research accomplished by the LASL H.5 Respirator Rescarch Group. Quantitative results from tests on personnel using half-mask respirators or full-face masks indicated that the full-face type provided better protection and less leakage than the half-face mask. Based on these results, the Dow Rocky Flats Executive Safety Committee recommended upgrading the respiratory protection program at Rocky Flats and the use of full-face masks in areas concerned with intermediate concentrations of toxic particulates. In addition, recommendations made by the USAEC Operativinal Safely Survey of February 1972 gave impetus to implementation of full-face masks at Rocky Flats.

The increased number of full-face masks dictated a complete change in laundry operations at Rocky Flats; specifically, hanges in methods of washing, repairing, inspection, and torage. It also required that a leak test be developed for the full-face masks after the laundry operation and subsequent to service use.
The test facility at Rocky Flats was designed to meet the requirements of American National Standard Practices for Respiratory Protection and Section 1910.134 of the Occupational Safety and Health Administration.

This report discusses the equipment and program developed at Rocky Flats for testing the leak-tight integrity of fullface masks.

\section{SUMMARY}

A respirator is essential for the protection of individuals encountering an atmosphere of hazardous particulates. The protective value is based primarily on the ability of the respirator to exclude airborne hazards, such as radioactive or toxic particulates, from being inhaled by personnel.

In this report we do not discuss chemical contaminants because they require other protective considerations.

After considerable investigation, which included contacting other AEC contractors and persons knowledgeable of respiratory equipment, the described method was developed as a standard for testing at Rocky Flats Division of Dow Chemical U.S.A.

\section{EQUIPMENT}

The test for the full-face-mask respirator incorporates the use of two systems:

1. The Q127 penetrometer system includes smoke-making and smoke-controlling equipment, particle size indicator and associated mechanical analyzer which monitors the smoke particle size, a percent-of-penetration indicator and an associated light-scattering chamber which measures the percent of smoke that penetrates the component being tested; plus piping, wiring, chuck assemblies, vacuum pump, and other components. This unit is referred to as the Q127 Filter Test Penetrometer System.

2. The Q14 test heads are part of a system used to evaluate the DOP smoke leakage of a protective mask assembly and component parts. This equipment is basically the same as the Q127 but does not incorporate the use 
of a particle size indicator and associated mechanical analyzer to monitor particle size. This unit is referred to as a Q14 Gas-Mask-Leakage tester. (Figure 1.)

Three sizes of test heads are available-small, medium, and large. The small and medium sizes were selected for our purpose. Only one make of full-face mask fits the small head. All other models fit the medium size head.

The test head is made of cast aluminum and has provisions for being mounted to a work surface. (Figure 2.) The head comes complete with an inflatable peripheral seal and provisions for pipe connections necessary for the vacuum hookup to operate the test.

These units are available commercially from Air Techniques, Incorporated, 1717 Whitehead Road, Baltimore, Maryland 21207.

\section{PROCEDURE}

Three pounds of dry, oil-free compressed air is required to inflate the peripheral tube. This air supply can come from the same source provided to the Q127. A three-way valve is used to control the air to either of the two heads. Tygon tubing is used to supply the air from the valve to the peripheral tube. (Figure 3.)

To operate the test heads in conjunction with the Q127, a vacuum or high pressure hose is secured to the hose connection on the head. This hose should be long enough to couple to the vacuum hose which is removed from the test chuck. (Figure 4.)

A high-efficiency-filter cartridge is attached to the $1 \frac{1}{2}$-inch nipple on the test head.

It was necessary to design a method of securing the fullface mask to the test head. The method selected is a variation of other designs and uses a $1 / 2$-inch-thick aluminum base plate 12 inches by 14 inches, with a cutout for the neck of the test head. Into this plate are threaded five toggle pads. (Figure 5.) Each is placed in a position relative to the five buckles which secure the head harness to the full-face mask. A $3 / 8$ inch by $1 \frac{3 / 4}{4}$ inch stud bolt is threaded into each toggle pad. Attached to the other end of the stud bolts are adjustable hooks. For a full-face mask having six buckles to secure the head harness, a bridle was designed to permit two top buckles to be retained by the top hook.

The combination of the toggle pads and the free floating base plate permits the operator to make adjustments that represent the normal fit of the full-face mask when worn by an individual. After the correct alignment is made, the plate is fastened to the work surface. Further adjustments can be made by the hook adjustments. Once this has been made and the baso plato cecured, no further adjustments are. necessary for that style mask.

With the Q127 calibrated to test high-efficiency filters, the test flow must be calibrated to $\mathbf{4 2 . 5}$ liters per minute or 85 liters per minute. Either is acceptable. The vacuum hose is removed from the test chuck and attached to thc hosc from the test head. The full-face mask is fitted to the test head by attaching the center or forehead buckle to the center retention hook. (Figure 6.) With each hand grasping the buckles nearest the chin, the mask is then drawn forward and down over the chin of the front portion of the test head. The remaining four retaining hooks are secured to the buckles. Tlie pei iplieral tube is thein inflated, sealing the mask to the test head.

Surplus DOP sinoke being exhausted from the aging chamber can be used to spray over the unit being tested. This proved to be adequate but the large volume produced prevented the operator from isolating leaks. This volume also affected the light-scattering chamber, increasing the purge time.

An alternate smoke probe was provided by installing a $1 / 2$-inch pipe nipple into the outlet pipe of the aging chamber. A $1 / 2$-inch Tygon tube long enough to reach from the aging chamber to the test head was attached to the $1 / 2$-inch nipple. A manually controlled air nozzle is then attached to the other end.

This type of smoke probe has less effect on the lightscattering chamber, and permits the operator to locate a leak and control the smoke.

The operator attaches the completely assembled full-face mask to the test head and closes the test chuck which activatcs the vacuum. He then uses the probe to spray the entire mask with smuke whlle lie inanipulates the lens area, cartridge and cartridge holder, exhalation valve assem. bly, speaker diaphram, and other parts. During llus time, he observes the penetration meter for leak indication. (Figures 7 and 8.)

The Rocky Flats standard for acceptance of a completely assembled full-face mask is the same acceptance standard as for a high-efficiency filter cartridge; that is, a full-face mask having a leak indication of more than $0.03 \%$ is considered unacceptable. Repair or adjustment to a used full-face mask can be made. If new full-face masks are found to be unacceptable for reasons other than factory dirt, lint, or dust, the manufacturer is notified. The manufacturer then determines what corrective action will be taken. 


\section{JISCUSSION}

This particular test method checks the integrity of the complete mask as an individual would wear it. If properly worn, the mask will provide the necessary respiratory protection.

The system can be used to test various styles of full-face masks, including types of supplied-air systems. The correct canister and air-flow requirements must be determined for the specific style and type to be tested.

This system also provides for testing high-efficiency filter cartridges to be used in half-mask respirators. This capability contributes to the quality assurance of the overall test program.

All new full-face masks and high-efficiency filter cartridges are tested at Rocky Flats before they are put into service. Used full-face masks and high-efficiency cartridges are tested before reissue.

\section{RESULTS OF TESTING METHOD}

The use of a particular high-efficiency cartridge was discontinued because the unit became unstable after being dropped.

A $20 \%$ rejection rate on new high-efficiency filter cartridges required the manufacturer to correct a punch-press operation.

Some of the full-face masks had a high leak rate around the welding lens attachment. Those masks were returned, and the manufacturer developed a new welding attachment which was tested and found acceptable.
One manufacturer designed a new cartridge holder and connector; another designed a new cartridge connector. Prototypes were tested and found acceptable.

A shipment of 400 full-face masks was rejected because of mold-release wax on the units.

Leaking control valves were found on new self-contained air supply masks purchased for the Rocky Flats Fire Department.

Lint, dirt, and dust have been found under the exhalation valve and voice diaphragm of the new full-face masks; and tests indicate that the majority of the new masks require extensive cleaning before they are acceptable.

\section{CONCLUSIONS}

To verify the reliability of our test results on the discontinued high-efficiency filter, welding attachment, and the prototype cartridge connector, we compared our findings with the H-5 Group at Los Alamos and found that our determinations were correct.

We also compared our test data on high-efficiency cartridges with one of the manufacturers and verified our results.

Daily observations indicate that a minimum of $30 \%$ of the used full-face masks tested require some form of maintenance before reissue and that $5 \%$ of the high-efficiency cartridges used over five times show some degree of damage, high resistance or high penetration. Rocky Flats' limit on reuse of high effieiency cartridges is four times.

The test method now in use at Rocky Flats is a standard operating procedure for a quality assurance check of highefficicncy cartridges and full-face masks. 
RFP-1997

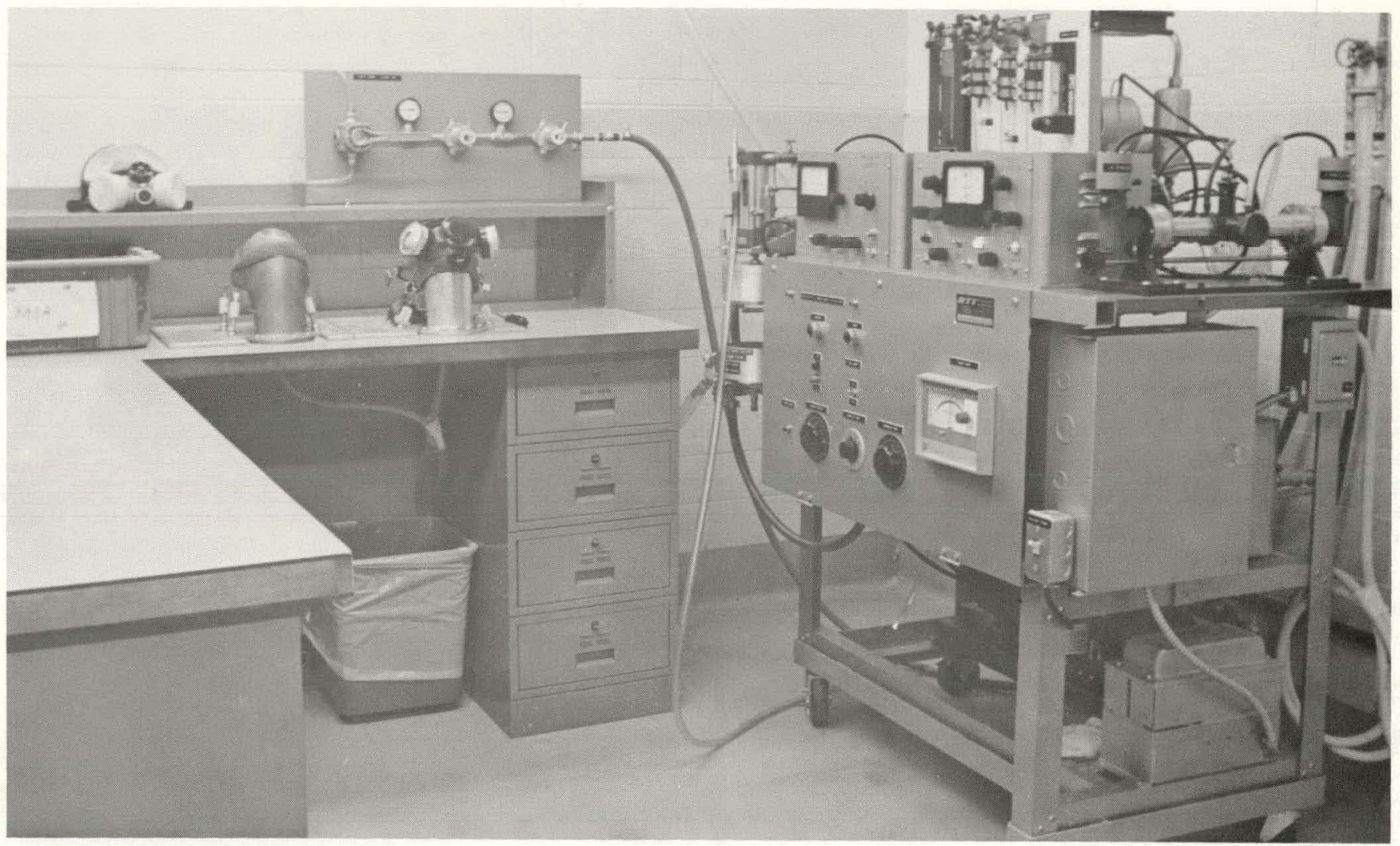

Figure 1. The $\mathrm{Q} 14$ Gas-Mask-Leakage Tester Unit.

Figure 2. Test Heads Mounted to Work Surface.

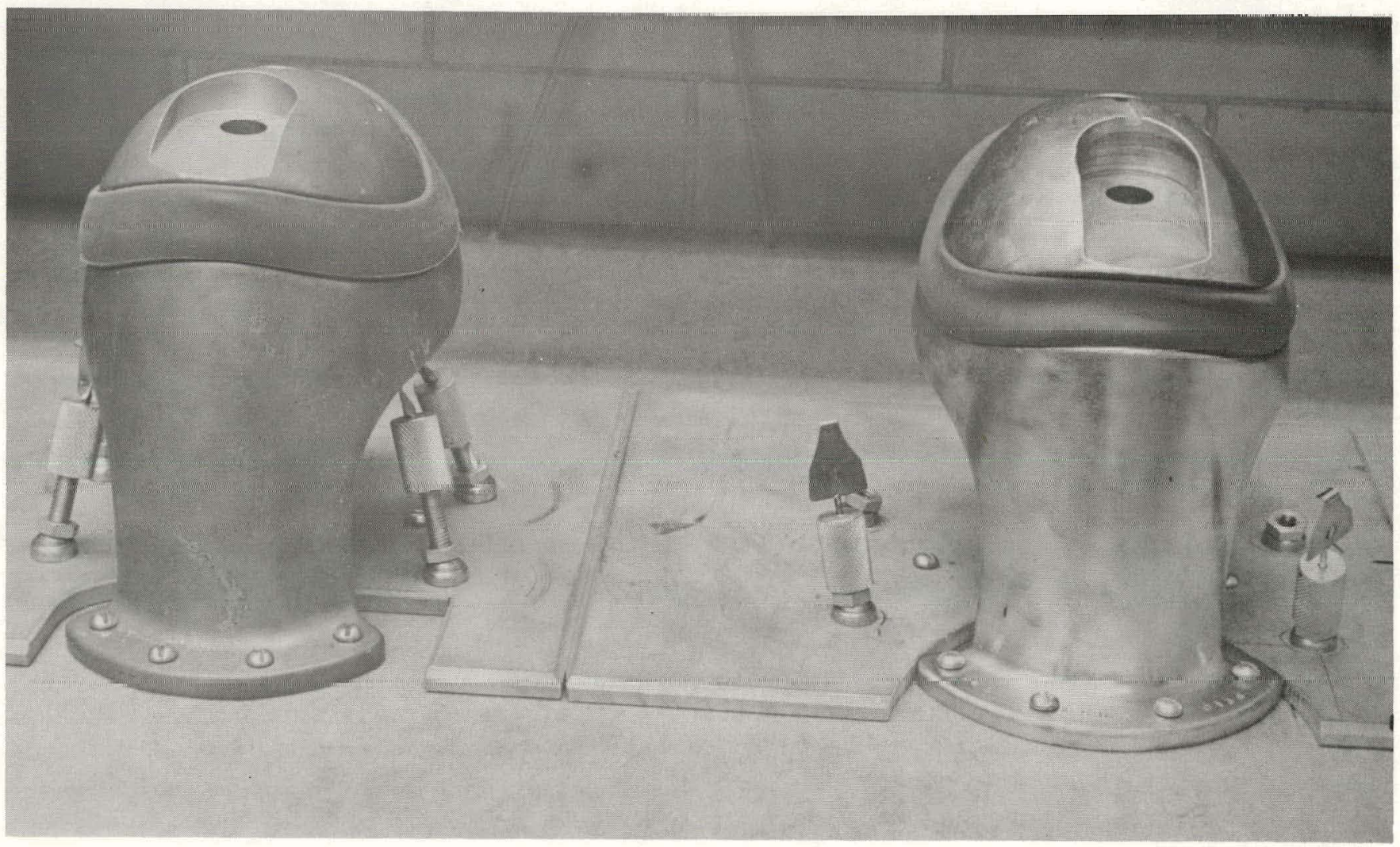




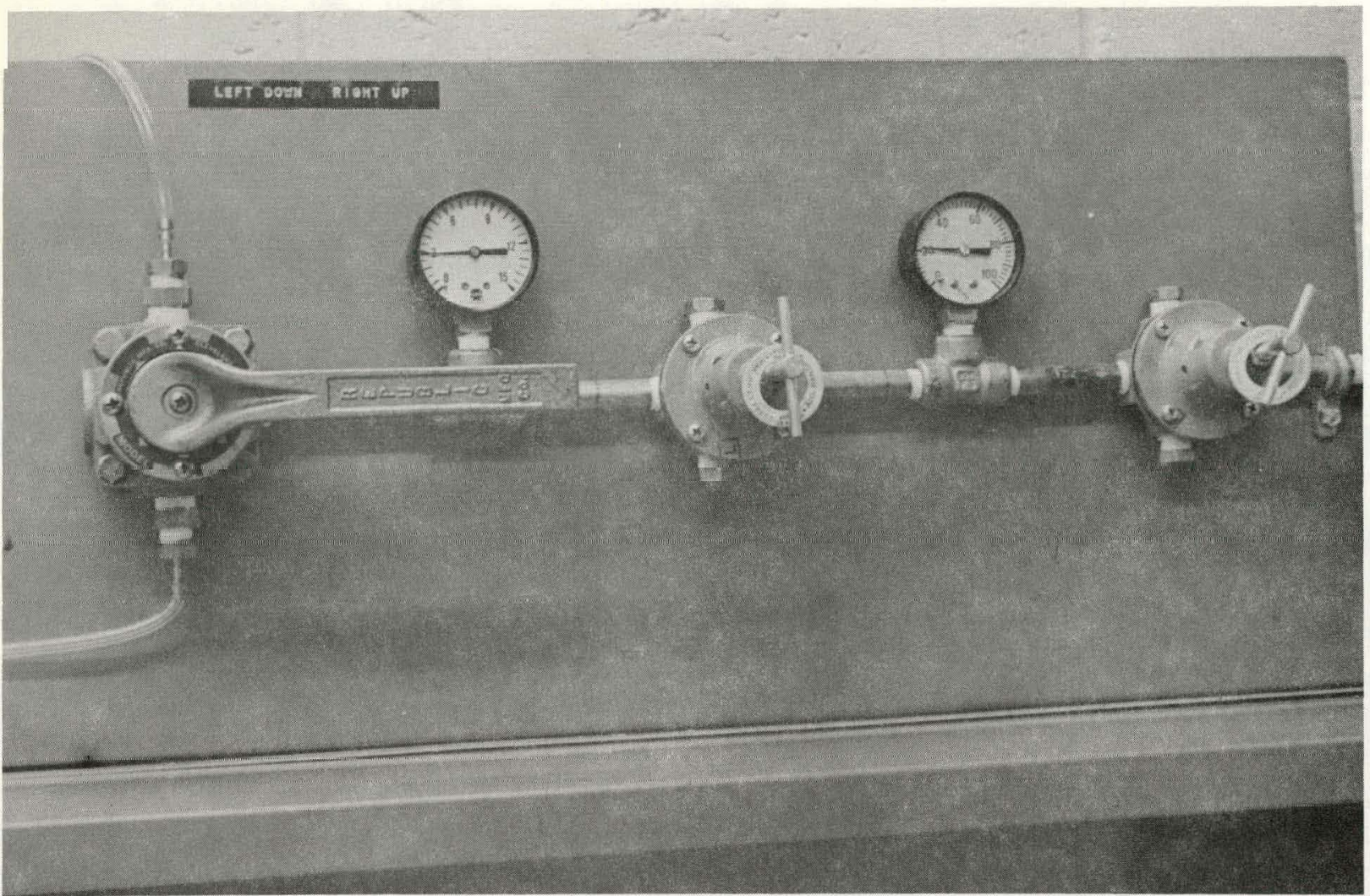

Figure 3. Air Valve Controls for Test Heads.

Figure 4. Vacuum Connection.

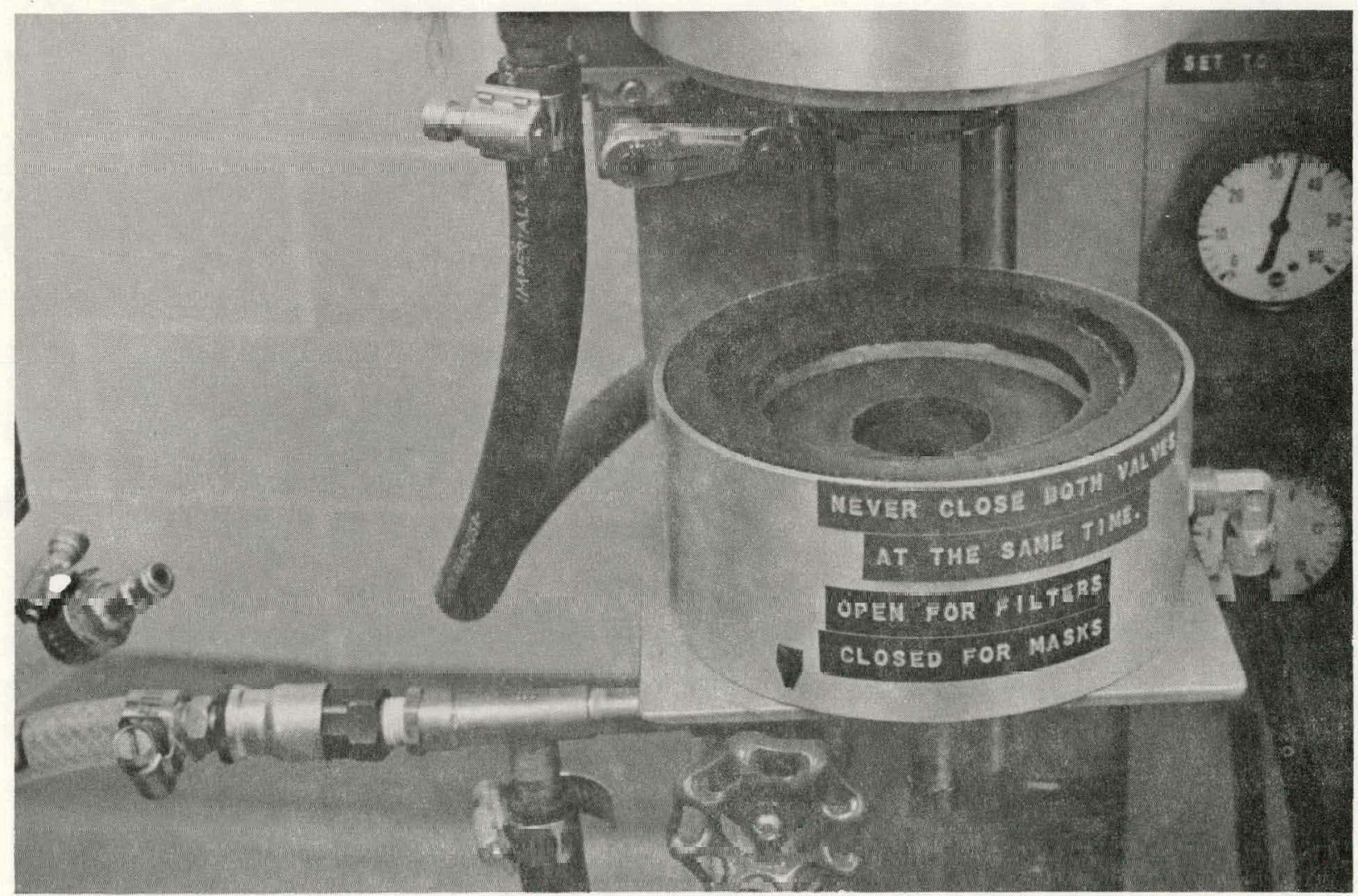




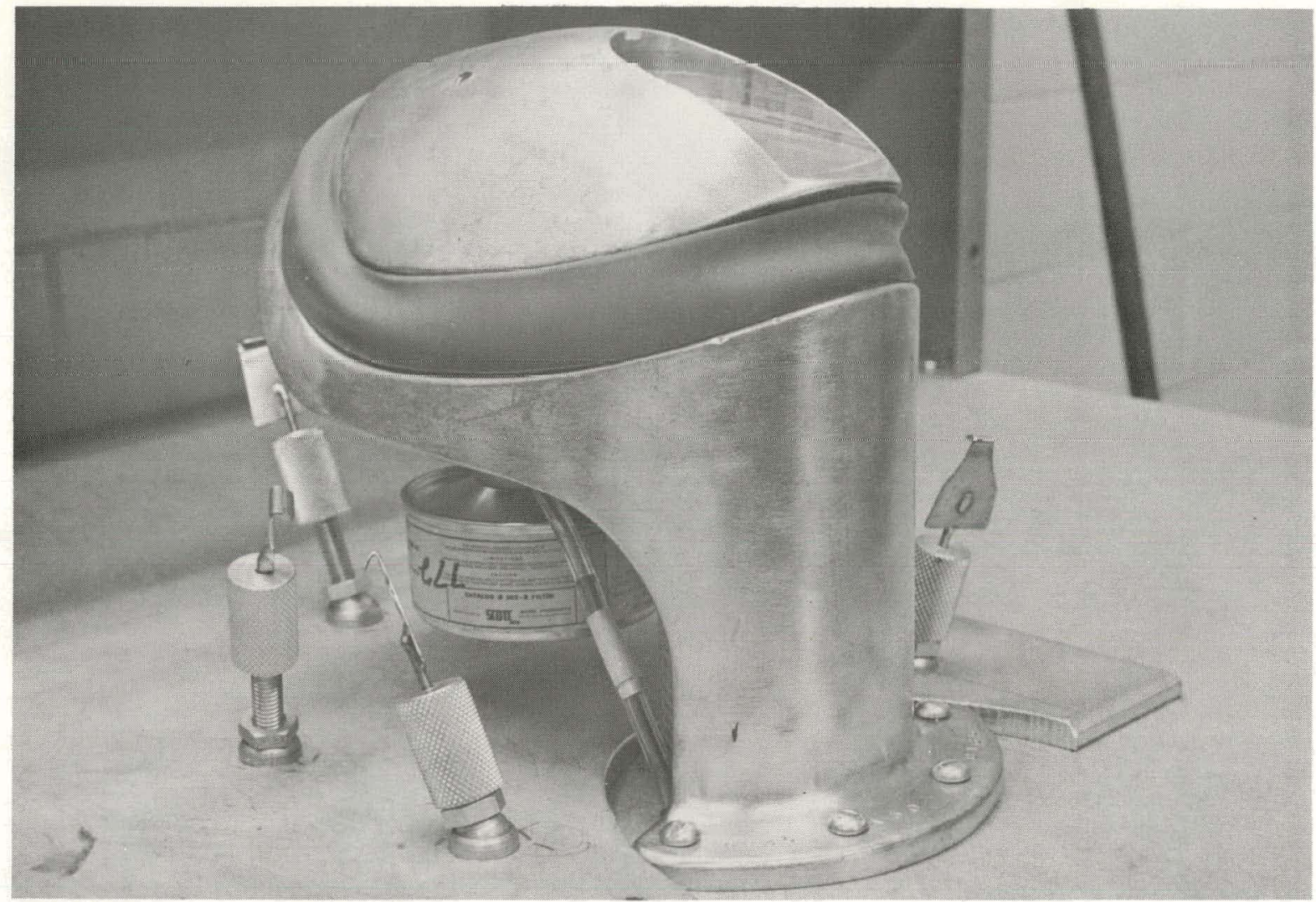

Figure 5. Test Head and Hold-Down Clamps.

Figure 6. Installing Full-Face Mask onto Test Head.

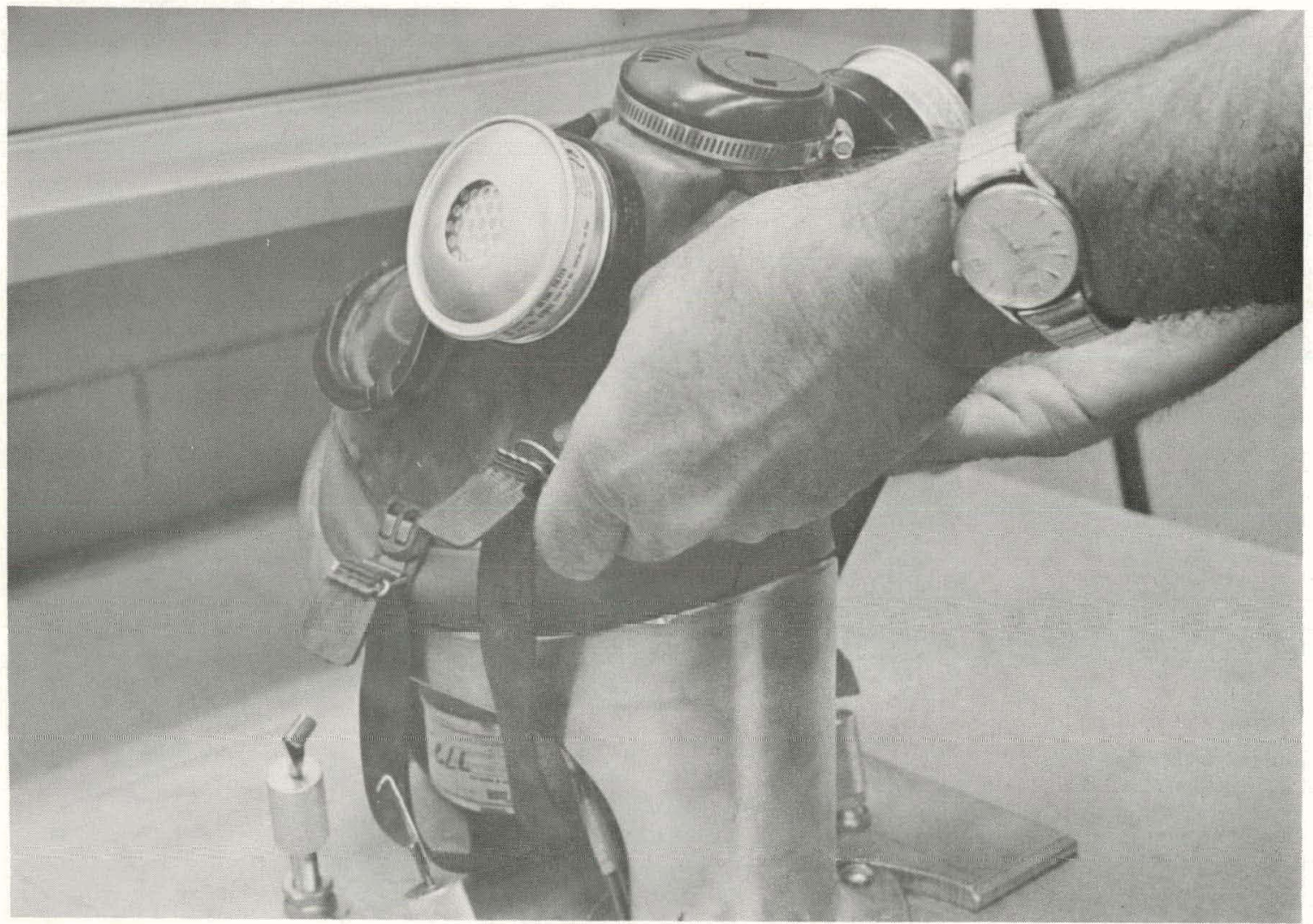


RFP-1997

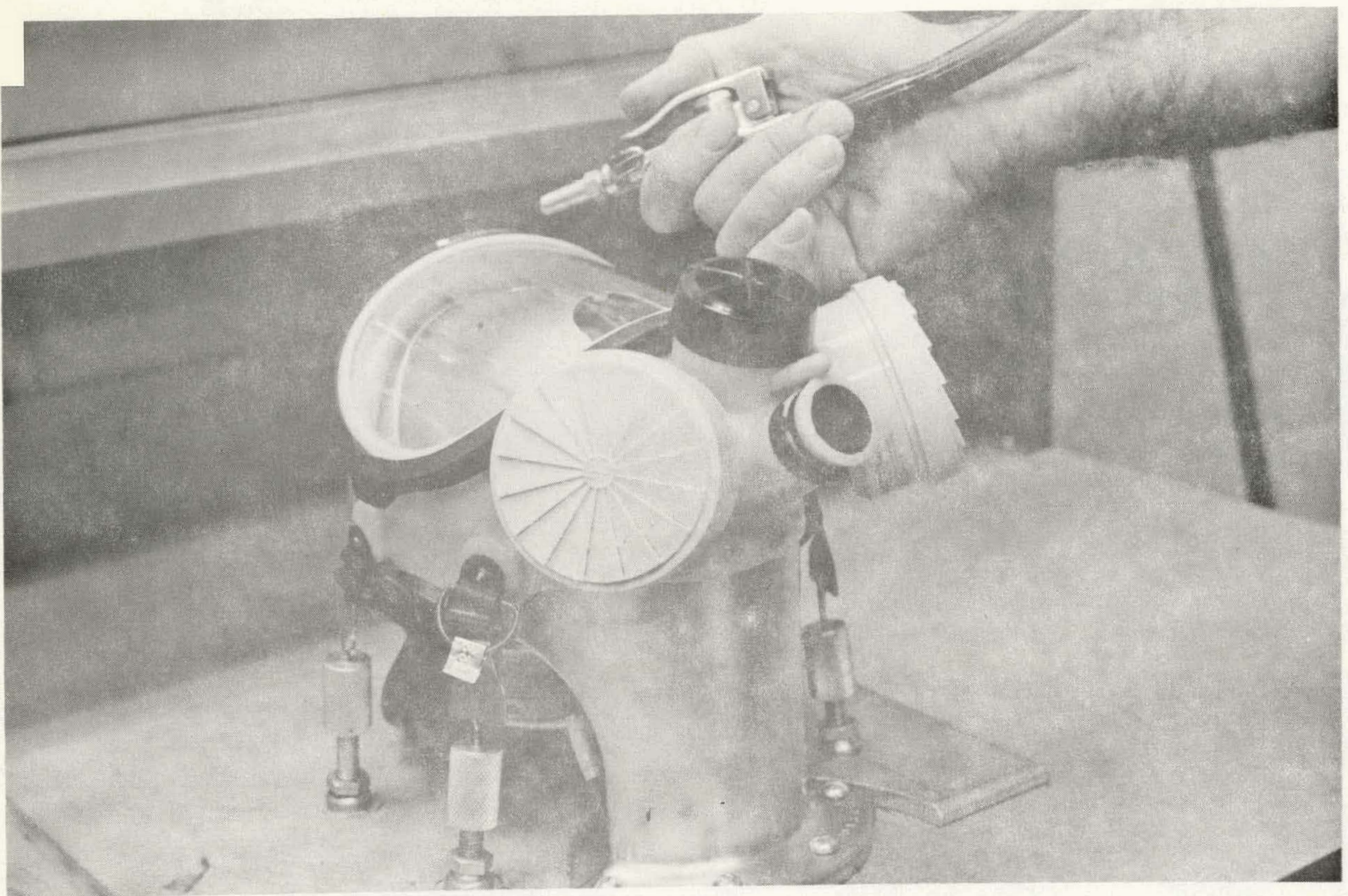

Figure 7. Testing with Test Probe.

Figure 8. Penetration Meter Indicating Leak.

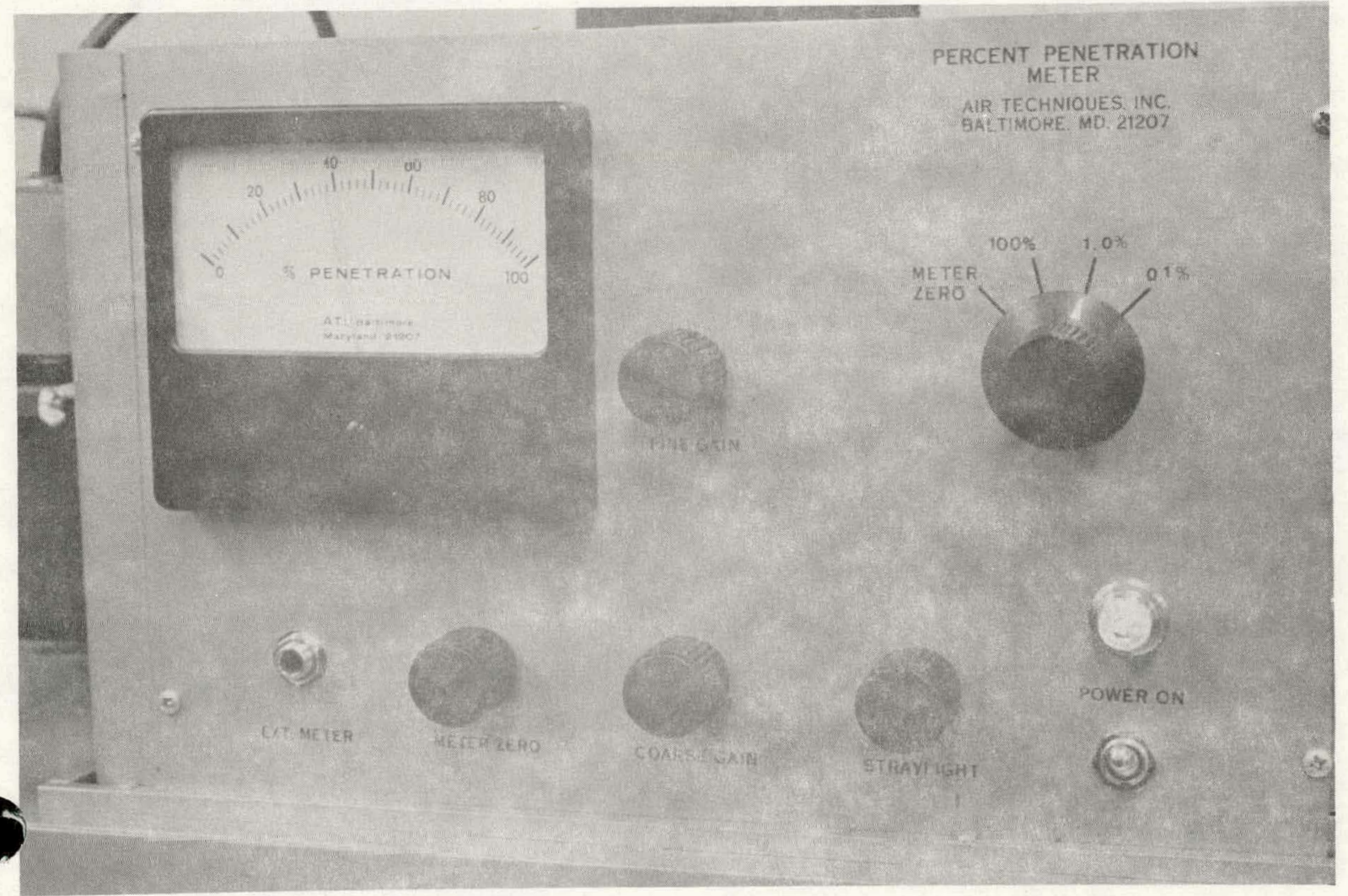

